\title{
Phylogenetic analysis of Endophytes from Bitter Melon (Momordica charantia) in Guangdong Province
}

\author{
Jianghua Huang1, Zide Jiang2 \\ ${ }^{1}$ Institute of Plant Pathology, Zhongkai University of Agricultue and Engineering, Guangzhou, China \\ ${ }^{2}$ Department of Plant Pathology, College of Natural Resources and Environment, South China Agriculture \\ University, Guangzhou, China \\ Email: jhhuang@139.com
}

Received 11 May 2015; accepted 27 June 2015; published 30 June 2015

Copyright (C) 2015 by authors and Scientific Research Publishing Inc.

This work is licensed under the Creative Commons Attribution International License (CC BY). http://creativecommons.org/licenses/by/4.0/

(c) () Open Access

\section{Abstract}

This study aims to isolate and identify taxonomic characterization of endophytic fungi from bitter melon in Guangdong province, China. A total of 1172 endophytic fungi are isolated from roots, stems, leaves, flowers, and fruits of healthy plants, and they are classified to 49 taxa based on morphological and molecular features. The results show that endophytic fungi from bitter melon plants exhibit high biodiversity. Arthrinium aureum, A. marii, A. sphaerospermum, Corynascus verrucosus, Curvularia borreriae and $C$. protuberate have not been recorded in any plants in China. Basidiomycetous endophytes, such as Ceratobasidium sp., and $C$. cornigerum, are reported in this study for the first time in bitter melon. According to the results of phylogenetic analysis, the rDNA ITS (Internal Transcribed Spacer) sequences can successfully separate species, such as $F$. solani, $F$. kyushuense, $C$. verrucosus, $C$. globosum, E. rostratum, $C$. brachyspora, $C$. verruculosus, $C$. affinis, $P$. bougainvilleicola, $P$. longicolla, $P$. glabrae, $P$. verruculosum, $P$. oxalicum, $P$. citrinum, $P$. chermesinum, $P$. glomerata, A. fumigatus and A. japonicas. Some isolates belonging to A. alternata, C. gloeosporioides, $C$. cladosporioides, $C$. brasiliense, $C$. convolutum, $F$. proliferatum, $F$. oxysporum, $F$. verticillioides, F. equiseti, F. camptoceras and Xylaria, however, require the analysis of others molecular markers to provide better taxonomic resolution. Molecular analyses of rDNA ITS sequences are useful for identification and classification of endophytes of bitter melon, but it is desirable to consider an integrated approach, such as molecular phylogeny, host, colony growth rate, symptoms, and shape of conidia.

\section{Keywords}

Endophytic Fungi, Momordica charantia, Phylogenetic Analysis 


\section{Introduction}

Endophytes inter- and/or intra-cellularly colonize healthy living tissues of many host plants, typically without causing any noticeable symptoms of disease [1]-[5]. Endophytic fungi from plants have recently been widely accepted as an important source of drugs [6], and they are believed to be rich in diversity and to provide an excellent potential source of biologically active novel compounds [7] [8]. Until recently, more than 8600 biologically active compounds have been reported from fungi with various usages [9].

Bitter melon (Momordica charantia), a medicinal food plant, is known to contain charantin (a steroidal glycoside), vicine (a glycoalkaloid), and polypeptide "p" (a 166 residue insulinomimetic peptide) [10]. Extracts of bitter melon have been found to possess novel bioactive natural products like antibacterial, antifungal, anticancer, antioxidant, antivirus and antidiabetes [11]. The medicinal characteristics of bitter melon may result from the capacity of its endophytes producing biologically active secondary metabolites.

rDNA ITS (Internal Transcribed Spacer) sequences analysis has been widely used in identifying fungi. Sette et al. (2006) identified endophytic fungi from coffee plants at least at the genus level, and the results were in accordance with the previous morphological characterization [12]. Chen et al. (2008) reported that ITS sequences analysis was especially effective in non-sporulating fungi identification and also reduced the impacts of subjective judgement [13].

The present study aimed to 1) identify endophytic fungi species from bitter melon in Guangdong Province in China, 2) conduct phylogenetic analysis on the ribosomal DNA internal transcribed spacer (ITS) region sequence of endophytes, and 3) collect cultures of endophytic fungi for further screening of the new bioactive compounds.

\section{Materials and Methods}

\subsection{Plant Materials}

Samples were collected between 2004 and 2009 from healthy bitter melon plants in five sites in Guangdong Province (Site 1: Huadu Station of the Guangzhou Vegetable Science Institute; Site 2: Forecast Station of Crop Diseases and Pests in Zhaoqing city; Site 3: Shitang town, Renhua county, Shaoguan city; Site 4: Xiangqiao district, Chaozhou city; and Site 5: Ducheng town, Yunan county, Yunfu city). Five healthy bitter melon plants (without visible signs of any disease) were collected from the each of the five sites. Each experimental field had fields of bitter melon at least $100 \mathrm{~m}^{2}$ large. The samples were placed in an ice-box and processed within $4 \mathrm{~h}$ of collection.

\subsection{Fungal Isolation and Cultivation}

Surface sterilization was applied as described by Schulz et al. (1993) [14]. The surface-sterilized samples of stem, root, flower, and fruit (all) were cut into $5 \times 5 \mathrm{~mm}$ fragments. A total of 30 fragments from different tissue type per site were prepared. Five fragments from surface-sterilized leaf discs or other organ segments were evenly placed on a $2 \%$ potato dextrose agar (PDA) medium. Fifty microgram streptomycin (AMRESCO)/ml were added to repress bacteria. These plates were incubated at $25^{\circ} \mathrm{C}$ for 2 months, and examined periodically. Hyphal tips of the developing fungal colonies were transferred onto new malt extract agar (MEA, 2\%) plates. The pure endophytic fungal strains were photographed and preserved in the Institute of Plant Pathology, Zhongkai University of Agriculture and Engineering.

\subsection{Checking Surface-Sterilization}

The method followed Song et al. (1999) [15]. A viability test was adopted to test the effectiveness of surfacesterilization [14].

\subsection{Identification}

Sporulating isolates were identified to genus and possible species using traditional morphological techniques. After subculture of isolates grown on PDA for 1 week at $25^{\circ} \mathrm{C}$, all pure strains were selected for DNA extraction, amplification, and sequencing [16]. DNA samples were checked for purity and integrity by electrophoresis in $1 \%$ $(\mathrm{w} / \mathrm{v})$ agarose with ethidium bromide $(10 \mathrm{mg} / \mathrm{mL})$ in $1 \times$ TAE buffer before storing at $4^{\circ} \mathrm{C}$. Primers ITS 4 and 
ITS5 [17] constructed for molecular phylogenetic studies were used to amplify the ITS region. PCR was carried out as follows: the reaction mix in a total volume of $25 \mu \mathrm{l}$ contained in font changed $0.2 \mathrm{mM}$ each of the primer pair, $0.2 \mathrm{mM}$ dNTP, 10 - 50 ng DNA, $0.04 \mathrm{U}$ of Taq polymerase (Promega, WI, USA), and $1 \times$ PCR buffer mix. Samples were incubated in a thermal cycler at $94^{\circ} \mathrm{C}$ for $3 \mathrm{~min}$, followed by 35 cycles of $94^{\circ} \mathrm{C}$ for $30 \mathrm{sec}, 55^{\circ} \mathrm{C}$ for $30 \mathrm{sec}, 72^{\circ} \mathrm{C}$ for $1 \mathrm{~min}$; and finally $72^{\circ} \mathrm{C}$ for $7 \mathrm{~min}$.

Phylogenetic analysis was based on blast searches of ITS sequence data in the NCBI GenBank database. Sequences were then aligned to other sequences obtained from the GenBank database with Clustal X 1.83 [18]. Phylogenetic analysis was performed with Mega 4.0 [19] using Kimura 2-parameter model with a transition to transversion ration. Phylogenetic trees were built using the neighbor-joining (NJ) methods [20]. Bootstrap tests were performed using 1000 replicates.

\section{Results}

\subsection{Species Identification}

Fungal endophytes were abundant and diverse in healthy plant tissues of bitter melon. Some of the isolates were non-sporulating and therefore difficult to identify decisively based on morphological characters. Based on morphological and molecular features, a total of 1172 endophytes were separated from bitter melon, and they were subsequently classified to 49 taxa (Table 1 ).

\subsection{Phylogenetic Analysis}

One hundred and eighteen strains, representing 49 taxa, were selected to sequence the internal transcribed spacer region (ITS) of nuclear ribosomal DNA.

Among the Fusarium, 30 strains formed five clades (Figure 1). Results showed that five strains of $F$. solani were clustered together with reference strains of F. solani, forming a unique lineage A1. Results also showed

Table 1. Endophytes of bitter melon in Guangdong province.

\begin{tabular}{|c|c|c|}
\hline Taxon & Sites & Tissues \\
\hline \multicolumn{3}{|l|}{ Ascomycetes } \\
\hline Alternaria alternata & Huadu & Flowers, leaves \\
\hline Arthrinium aureum & Huadu & Fruits, leaves \\
\hline A. marii & Huadu & fruits \\
\hline A. sphaerospermum & Yunfu & Stems \\
\hline Aspergillus fumigatus & Zhaoqing & Flowers \\
\hline Annulohypoxylon atroroseum & Zhaoqing & Leaves \\
\hline A. nitens & Zhaoqing & Leaves \\
\hline Ascomycete & Huadu & Fruits \\
\hline Aureobasidium pullulans & Zhaoqing & Fruits \\
\hline Bionectria ochroleuca & Chaozhou & Leaves \\
\hline Botryosphaeria rhodina & Zhaoqing & Stems \\
\hline B. dothidea & Zhaoqing & Fruits \\
\hline Chaetomium brasiliense & Huadu & Roots \\
\hline C. globosum & Huadu & Roots \\
\hline C. hexagonosporum & Huadu & Leaves \\
\hline C. madrasense & Huadu & Leaves \\
\hline \multirow[t]{2}{*}{ Cladosporium cladosporioides } & Zhaoqing & Leaves, fruits \\
\hline & Huadu & Fruits, leaves \\
\hline
\end{tabular}




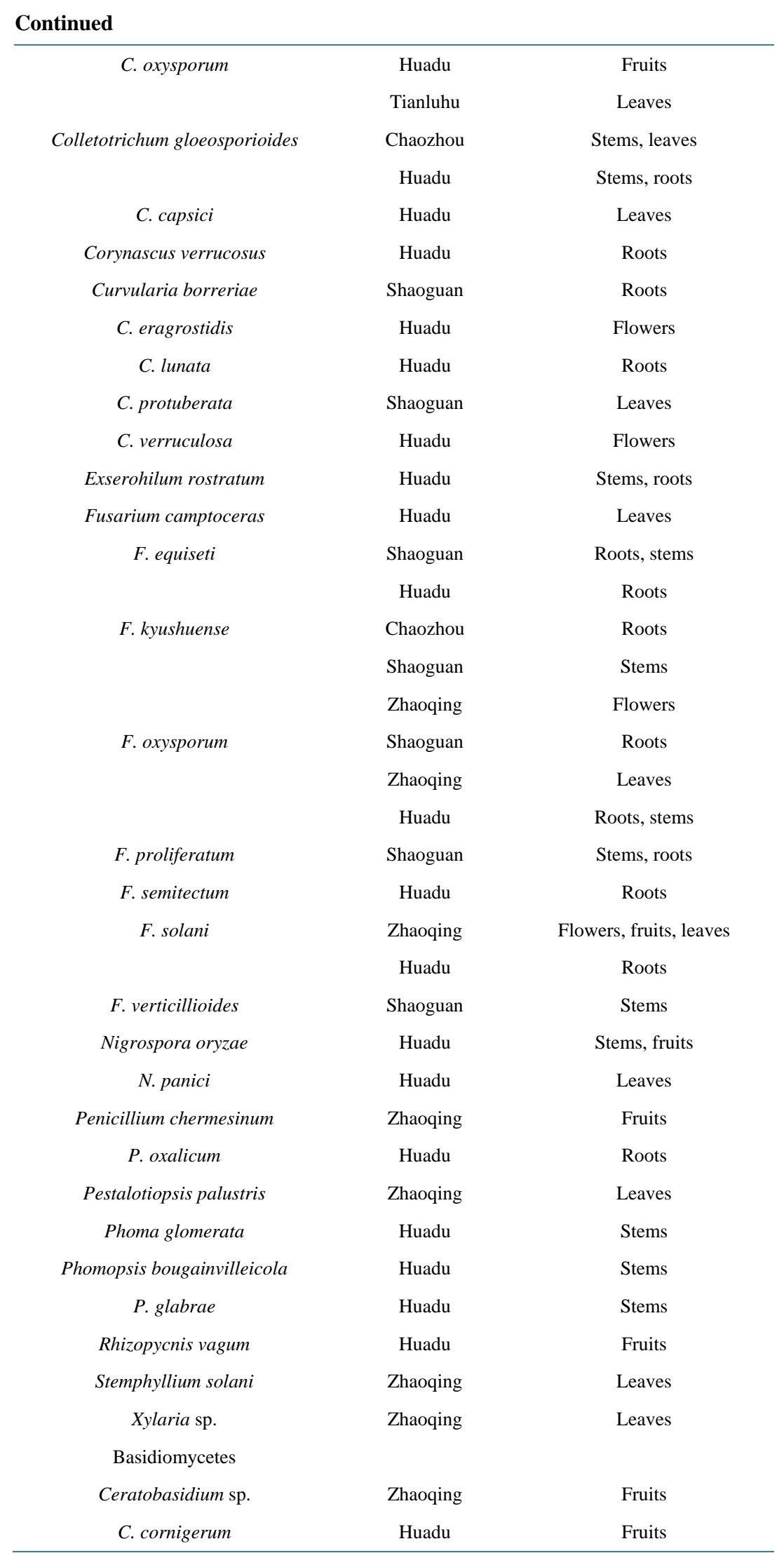




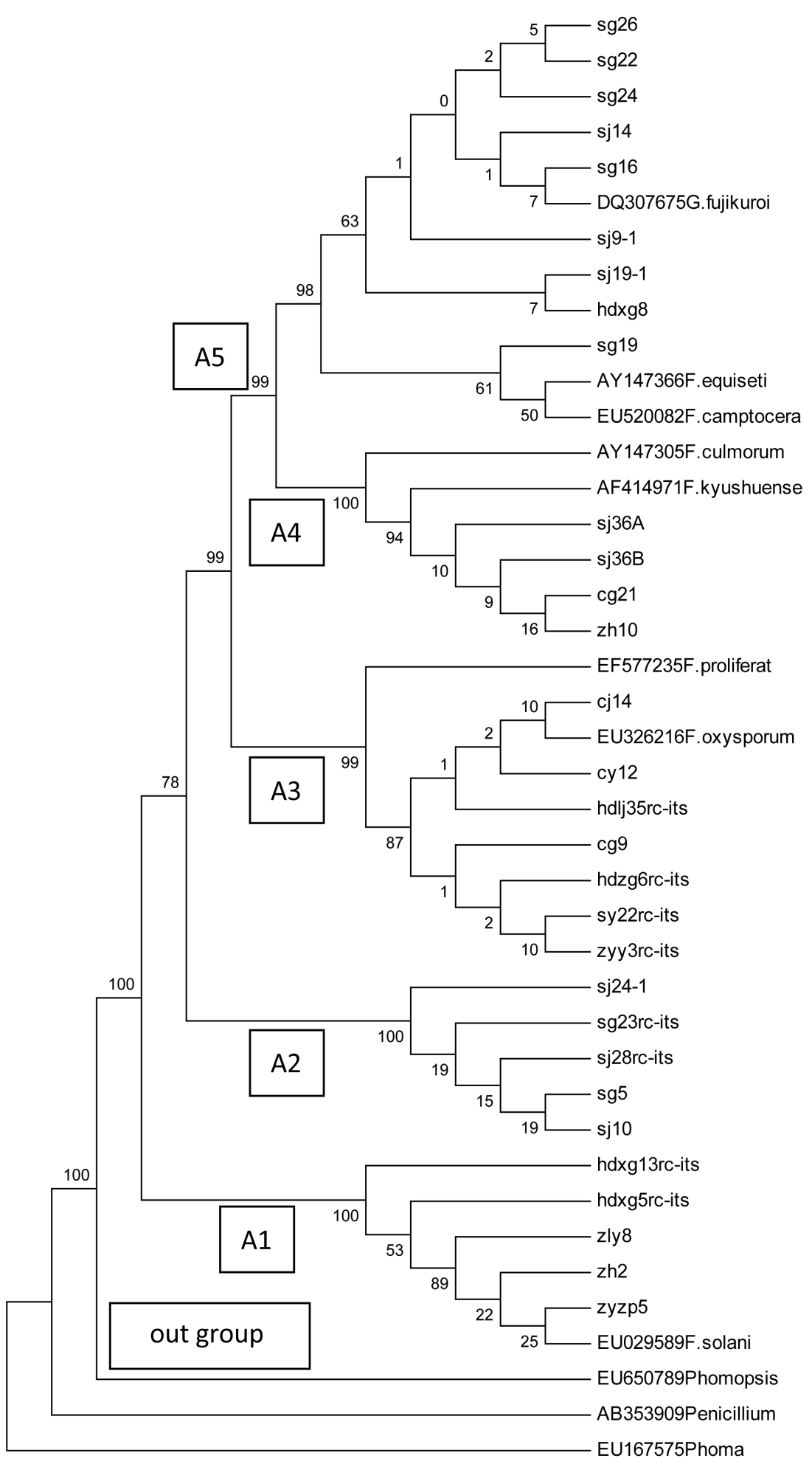

Figure 1. A neighbor-joining tree was generated based on the 5.8S gene and internal transcribed spacer (ITS1 and ITS2) sequences of 38 taxa of Fusarium, rooted with Penicillium marneffei, Phomopsis longicolla and Phoma medicaginis with Clustal W. The numbers at branches indicated the percentages from 1000 bootstrap replications in which the branch occurred. 


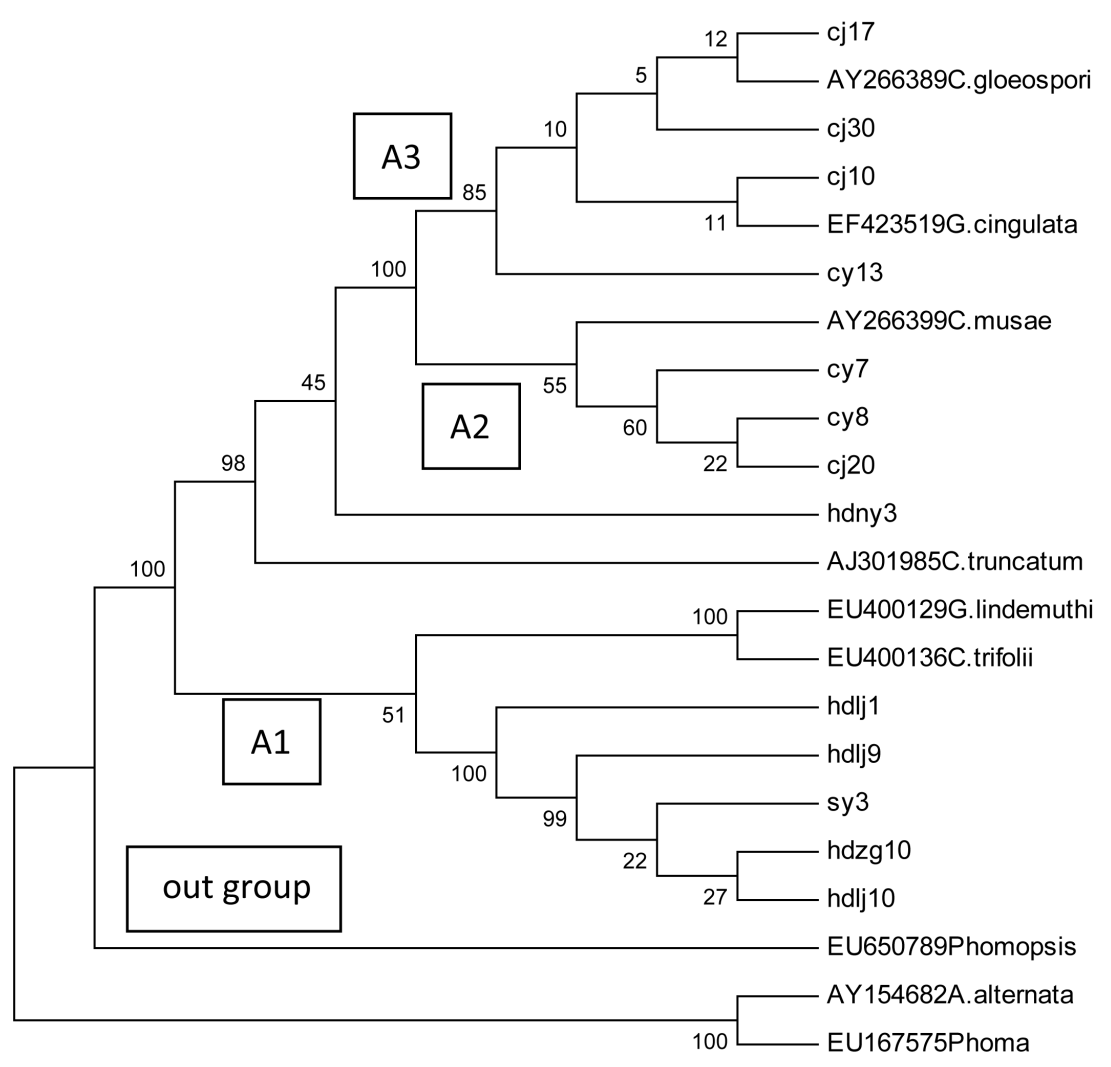

Figure 2. A neighbor-joining tree was generated based on the 5.8S gene and internal transcribed spacer (ITS1 and ITS2) sequences of 19 taxa of Colletotrichum, rooted with Alternaria alternata, Phomopsis longicolla and Phoma medicaginis with Clustal W. The numbers at branches indicated the percentages from 1000 bootstrap replications in which the branch occurred.

that three strains of $F$. proliferatum, one strains of $F$. oxysporum, and one strains of $F$. verticillioides were clustered together, forming lineage A2. Seven strains of $F$. oxysporum were clustered together with reference strains of $F$. oxysporum and $F$. proliferatum, forming a unique lineage A3. Four strains of $F$. kyushuense were clustered together with reference strains of $F$. kyushuense and F. culmorum, forming a unique lineage A4. Four strains of $F$. equiseti and five strains of $F$. camptoceras were clustered together with reference strains of $F$. equiseti, $F$. camptoceras and Gibberalla fujikuroi, forming lineage A5.

Among the Colletotrichum, 13 strains formed three clades (Figure 2). Results showed that five strains of $C$. gloeosporioides were clustered together with reference strains of Glomerella lindemuthiana and C. trifolii, forming a unique lineage A1. Results also showed that three strains of $C$. gloeosporioides were clustered together with reference strains of $C$. musae, forming lineage A2. Four strains of $C$. gloeosporioides were clustered together with reference strains of $C$. gloeosporioides and $G$. cingulata, forming a unique lineage A3.

Among the Cladosporium, 12 strains formed three clades (Figure 3). Results showed that one strain of $C$. cladosporioides formed a unique lineage A1. Six strains of $C$. cladosporioides were clustered together with reference strains of C. chlorocephalum, C. oxysporum, C. colocasiae, C. tenuissimum, C. cladosporioides and C. gossypiicola, forming lineage A2-1. Five strains of $C$. cladosporioides were clustered together, forming a unique lineage A2-2.

Among the Alternaria, 8 strains formed one clade (Figure 4). Results showed that eight strains of A. alternata were clustered together with reference strains of A. alternata, A. longipes, A. arborescens, A. tenuissima, forming lineage $\mathrm{A}$.

Among the Corynascus and Chaetomium, 6 strains formed three clades (Figure 5). Results showed that one strain of $C$. brasiliense, one strain of $C$. convolutum, and one unidentified strain were clustered together with reference strains of $C$. sp, forming lineage A1. One strain of $C$. verrucosus was clustered with reference strains 


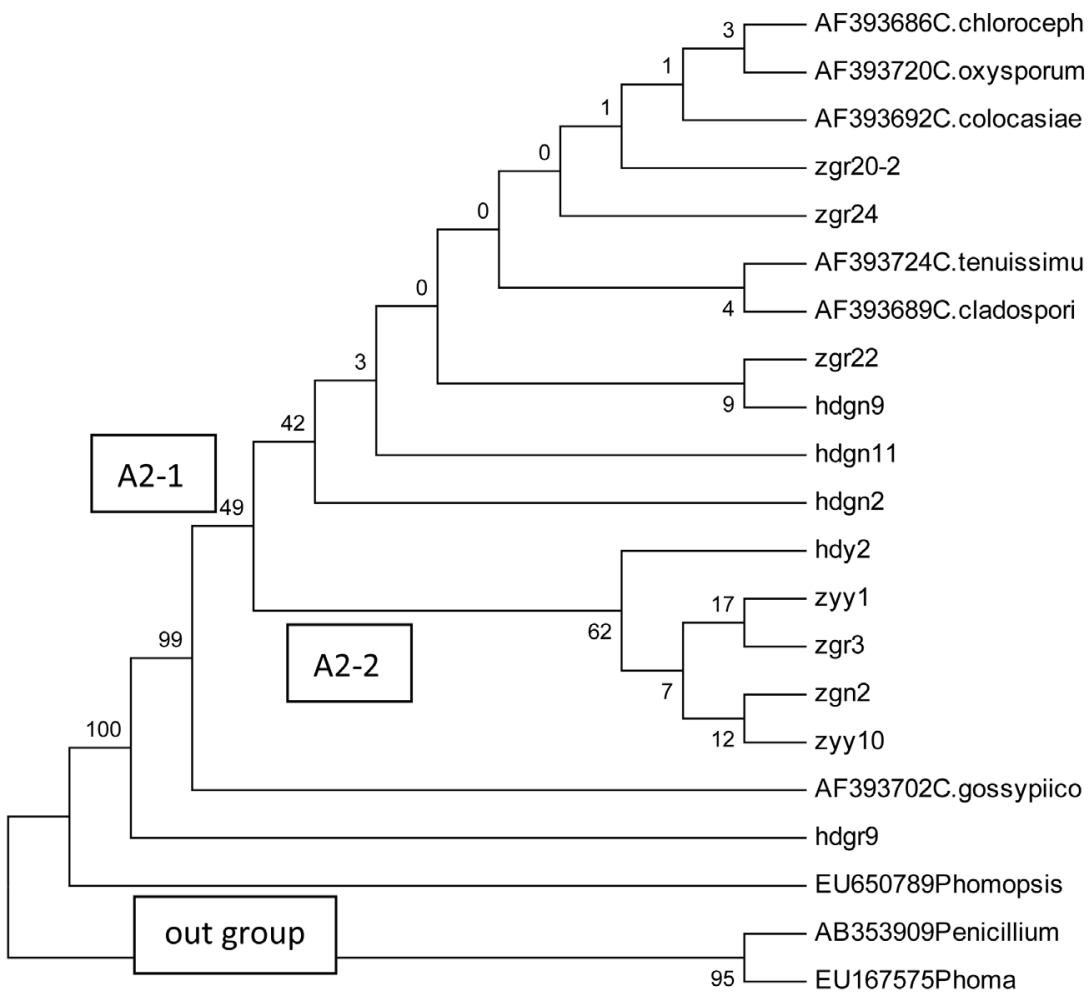

Figure 3. A neighbor-joining tree was generated based on the 5.8S gene and internal transcribed spacer (ITS1 and ITS2) sequences of 18 taxa of Cladosporium, rooted with Penicillium marneffei, Phomopsis longicolla and Phoma medicaginis with Clustal W. The numbers at branches indicated the percentages from 1000 bootstrap replications in which the branch occurred.

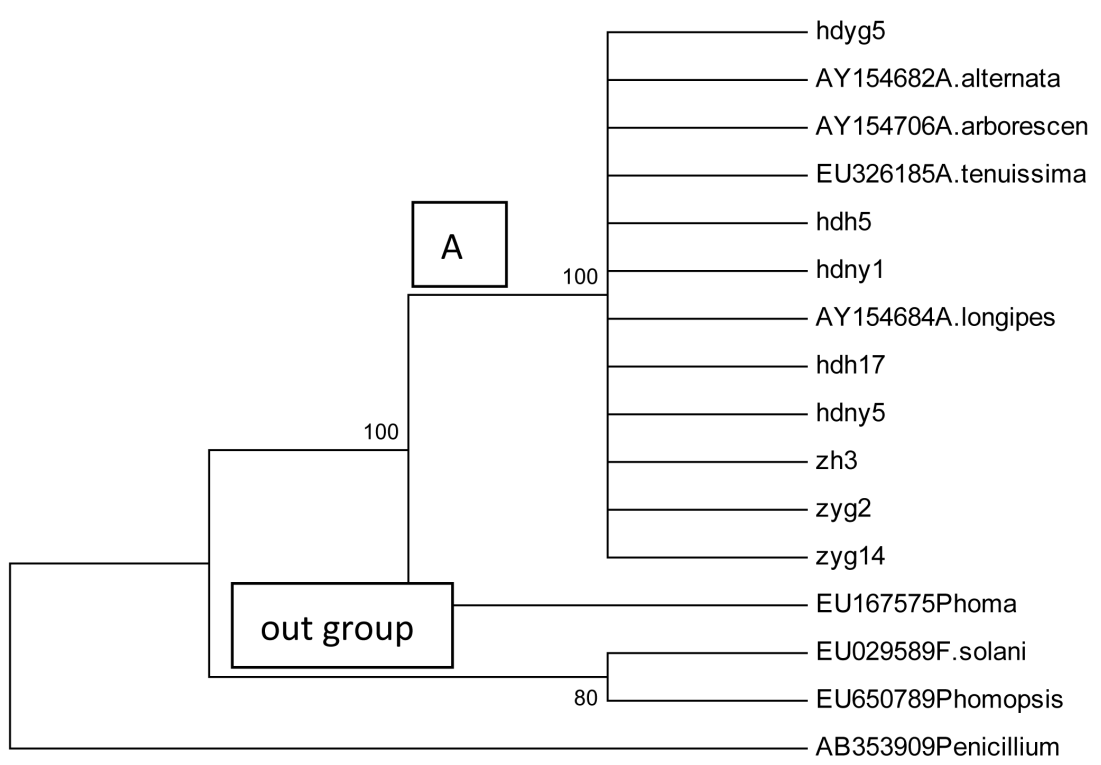

Figure 4. A neighbor-joining tree was generated based on the $5.8 \mathrm{~S}$ gene and internal transcribed spacer (ITS1 and ITS2) sequences of 12 taxa of Alternaria, rooted with Fusarium solani, Penicillium marneffei, Phomopsis longicolla and Phoma medicaginis with Clustal W. The numbers at branches indicated the percentages from 1000 bootstrap replications in which the branch occurred. 
of C. verrucosus, and C. kuwaitiensis, forming a unique lineage A2. Two strains of C. globosum were clustered together with reference strains of C. globosum, and C. bostrychodes, forming a unique lineage A3.

Among the Curvularia, Exserohilum and Bipolaris, 7 strains formed five clades (Figure 6). Results showed that three strains of $E$. rostratum were clustered with reference strains of E. rostratum, E. pedicellatum, and $E$. longirostratum, forming a unique lineage A1. One strain of $C$. brachyspora was clustered with reference strains

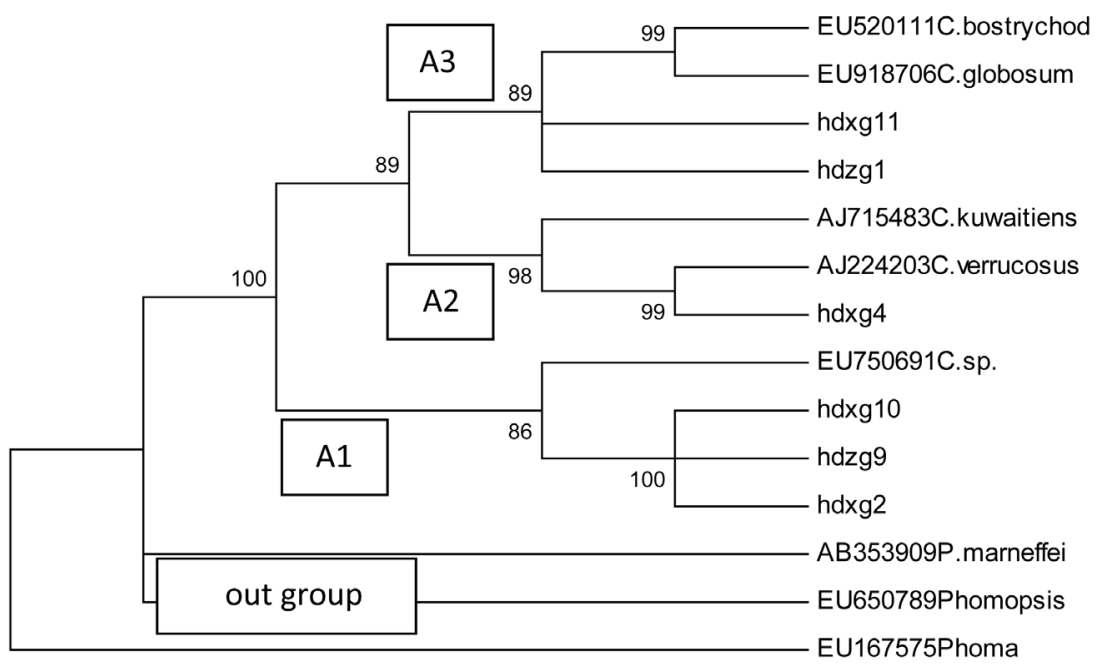

Figure 5. A neighbor-joining tree was generated based on the 5.8S gene and internal transcribed spacer (ITS1 and ITS2) sequences of 6 taxa of Corynascus and Chaetomium, rooted with Penicillium marneffei, Phomopsis longicolla and Phoma medicaginis with Clustal W. The numbers at branches indicated the percentages from 1000 bootstrap replications in which the branch occurred.

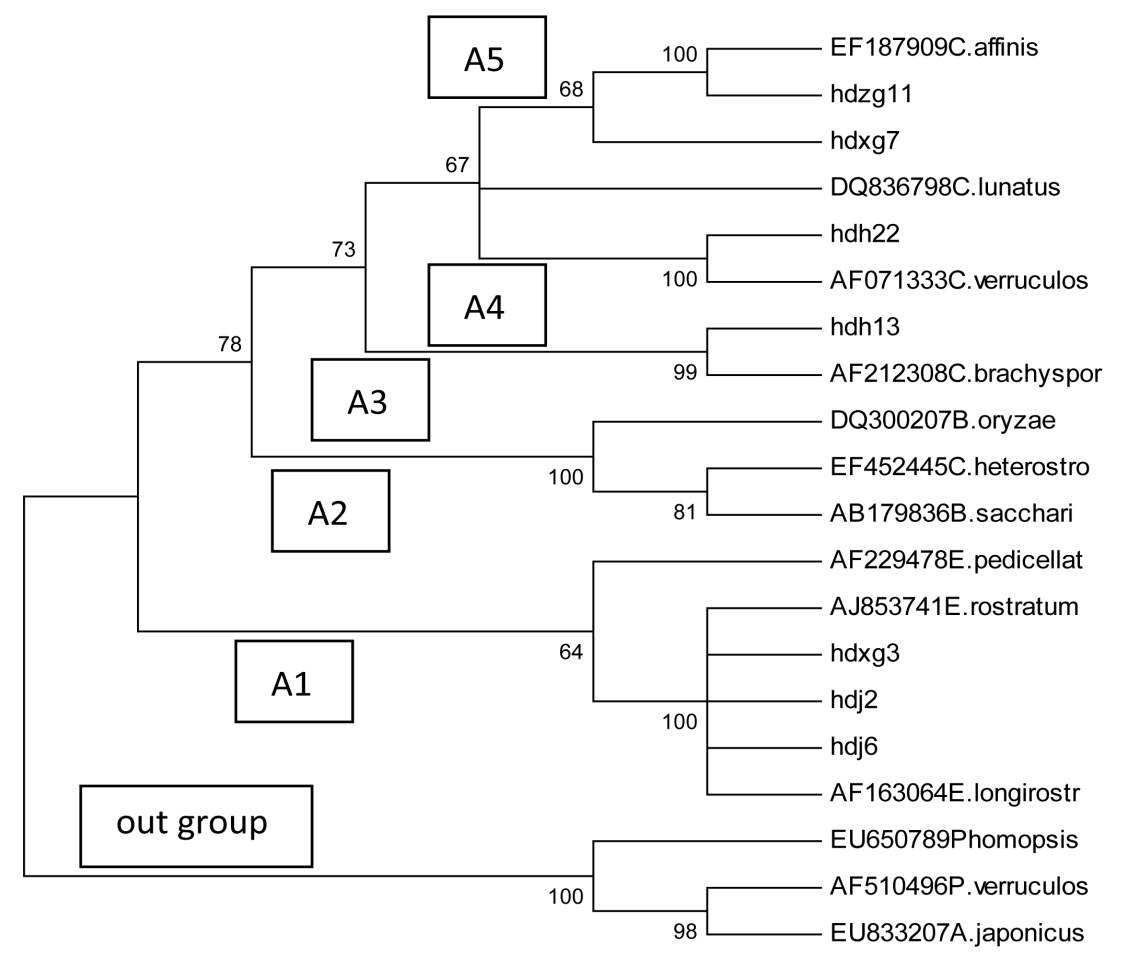

Figure 6. A neighbor-joining tree was generated based on the 5.8S gene and internal transcribed spacer (ITS1 and ITS2) sequences of 17 taxa of Curvularia, Exserohilum and Bipolaris, rooted with Penicillium verruculosum, Phomopsis longicolla and Aspergillus japonicus with Clustal W. The numbers at branches indicated the percentages from 1000 bootstrap replications in which the branch occurred. 
of $C$. brachyspora, forming a unique lineage A3. One strain of $C$. verruculosus was clustered with reference strains of $C$. verruculosus, forming a unique lineage A4. One strain of $C$. affinis was clustered together with reference strains of $C$. affinis, forming a unique lineage A5.

Among the Phomopsis, 4 strains formed three clades (Figure 7). Results showed that one strain of P. bougainvilleicola was clustered with reference strains of $P$. bougainvilleicola, forming a unique lineage A1. One strain of $P$. longicolla was clustered with reference strains of $P$. longicolla, forming a unique lineage A2. Two strains of $P$. glabrae were clustered with reference strains of $P$. glabrae, forming a unique lineage A3.

Among the Penicillium, 5 strains formed four clades (Figure 8). Results showed that two strains of $P$. verruculosum were clustered with reference strains of $P$. verruculosum, and $P$. marneffei, forming a unique lineage A1.

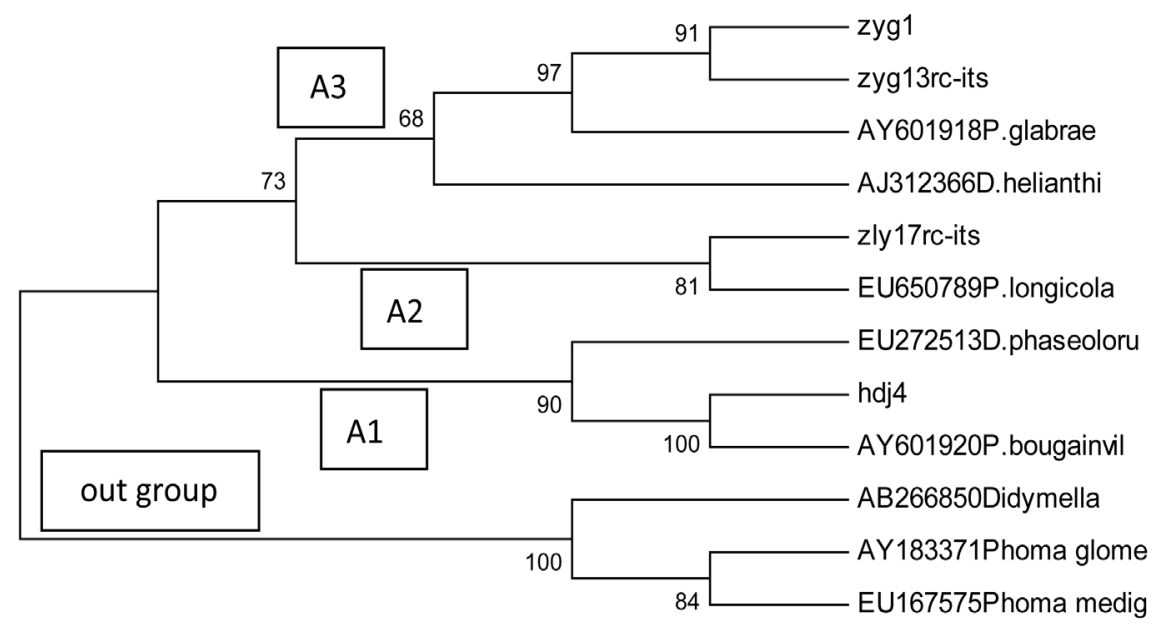

Figure 7. A neighbor-joining tree was generated based on the 5.8S gene and internal transcribed spacer (ITS1 and ITS2) sequences of 9 taxa of Phomopsis, rooted with Didymella bryoniae, Phoma glomerata and Phoma medicaginis with Clustal W. The numbers at branches indicated the percentages from 1000 bootstrap replications in which the branch occurred.

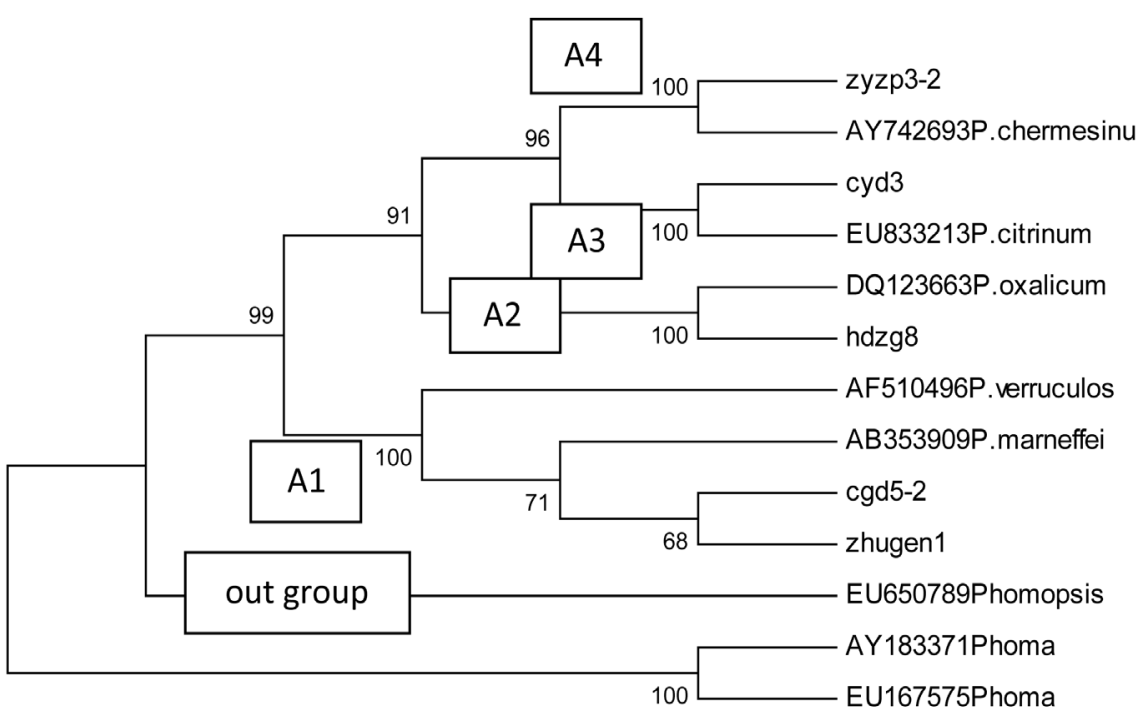

Figure 8. A neighbor-joining tree was generated based on the 5.8S gene and internal transcribed spacer (ITS1 and ITS2) sequences of 10 taxa of Penicillium, rooted with Phomopsis longicolla, Phoma glomerata and Phoma medicaginis with Clustal W. The numbers at branches indicated the percentages from 1000 bootstrap replications in which the branch occurred. 
One strain of $P$. oxalicum was clustered with reference strains of $P$. oxalicum, forming a unique lineage A2. One strain of $P$. citrinum was clustered with reference strains of $P$. citrinum, forming a unique lineage A3. One strain of $P$. chermesinum was clustered with reference strains of $P$. chermesinum, forming a unique lineage A4.

Among the Phoma, 7 strains formed three clades (Figure 9). Results showed that six strains of Phoma was clustered with reference strains of P. glomerata, and Didymella bryoniae (anamorph: P. cucurbitacearum), forming a unique lineage A1. One strain of Phoma formed a unique lineage A3.

Among the Aspergillus, 5 strains formed two clades (Figure 10). Results showed that four strains of A. fumigatus were clustered with reference strains of A. fumigatus, forming a unique lineage A1. One strain of A. japonicus was clustered with reference strains of $A$. japonicus, forming a unique lineage A2.

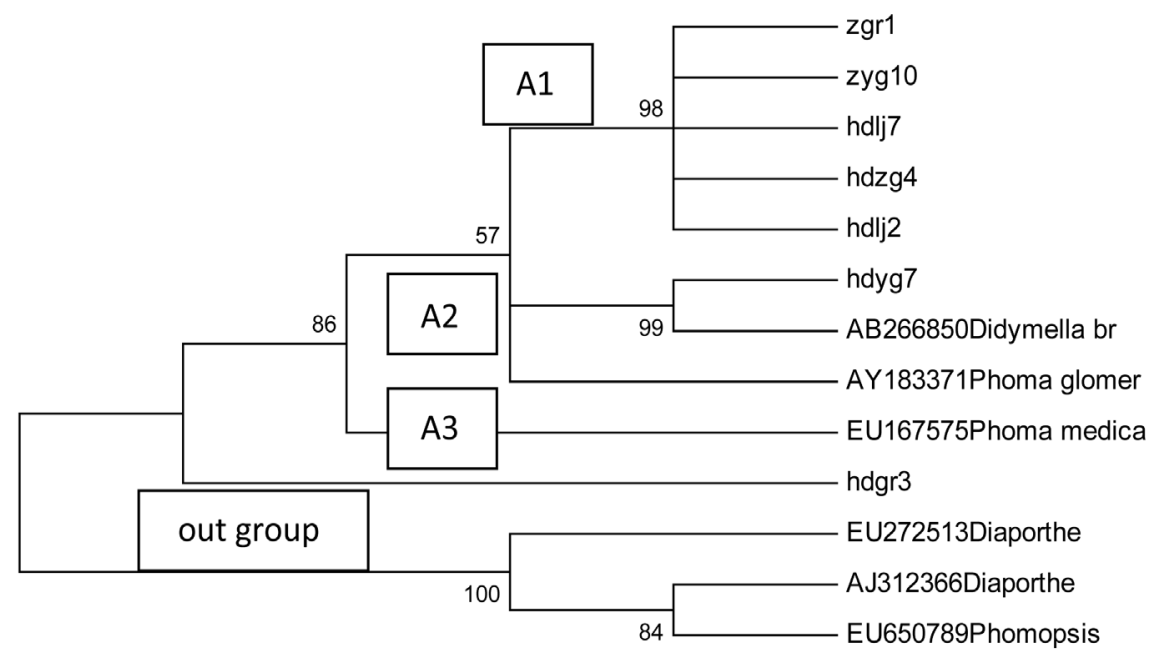

Figure 9. A neighbor-joining tree was generated based on the 5.8S gene and internal transcribed spacer (ITS1 and ITS2) sequences of 10 taxa of Phoma, rooted with Phomopsis longicolla, Diaporthe phaseolorum and Diaporthe helianthi with Clustal W. The numbers at branches indicated the percentages from 1000 bootstrap replications in which the branch occurred.

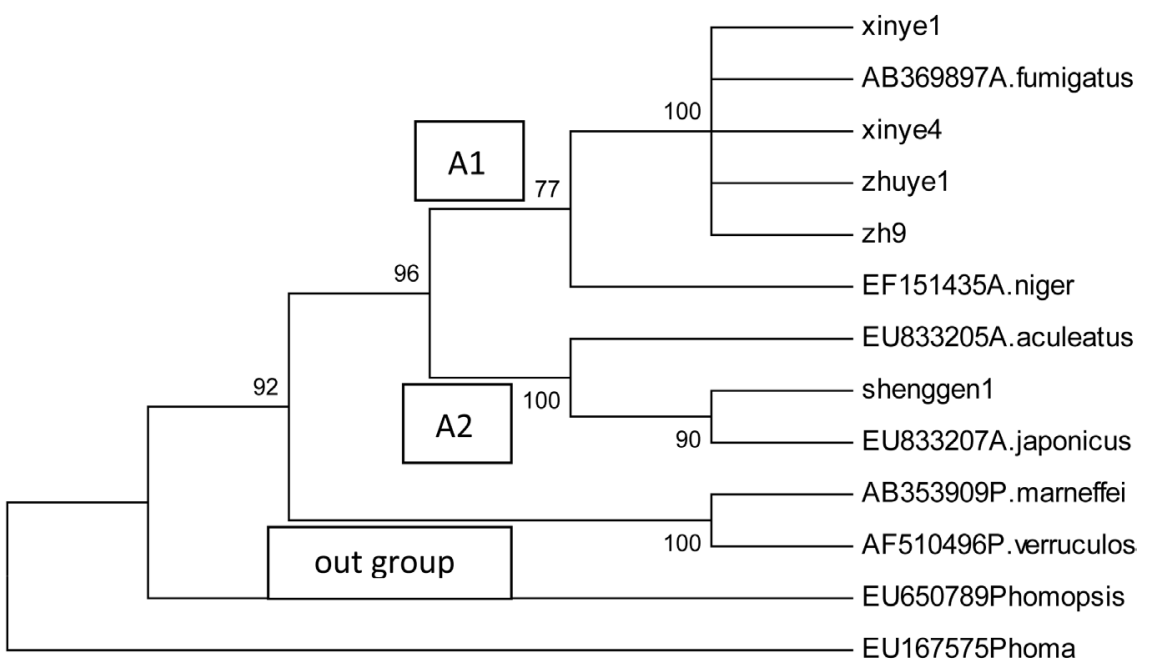

Figure 10. A neighbor-joining tree was generated based on the 5.8S gene and internal transcribed spacer (ITS1 and ITS2) sequences of 9 taxa of Aspergillus, rooted with Phomopsis longicolla, Phoma medicaginis, Penicillium marneffei and Penicillium verruculosum with Clustal W. The numbers at branches indicated the percentages from 1000 bootstrap replications in which the branch occurred. 


\section{Discussion}

Traditional approaches to identifying fungal endophytes rely on microscopic analysis of morphological characteristics. However, significant portions of endophytic isolates consist of sterile mycelia and cannot be identified based on traditional approaches. Phylogenetic analysis of rDNA sequences has been successfully employed for the identification of different morphospecies [21]-[26]. In the present study, there are 49 taxa isolated as endophytic fungi from bitter melon. We conduct molecular phylogenetic analyses of endophytes of bitter melon, and build the phylogenetic tree from ITS sequences between species of the same genus or between the similar genera. Morphological characters, together with DNA sequence information, can be used to identify the endophytic strains.

The endophytic fungi associated with bitter melon comprise a number of cosmopolitan species such as Alternaria alternata, Aspergillus fumigatus, Colletotrichum gloeosporioides and Curvularia lunata. All these genera have been previously isolated as endophytes, not only in Taxus species [25]-[28], but also in pharmaceutical plants [5] [6] [29] [30]. Arthrinium aureum, A. marii, A. sphaerospermum, Corynascus verrucosus, Curvularia borreriae, C. protuberate, however, have not been recorded in any host plants in China, suggesting that bitter melon harbours novel and diverse fungi. Most fungi reported as endophytes up to date have been identified as ascomycetes and their anamorphs. Basidiomycetous endophytes have only been reported in a few studies [24] [31]-[34]. Basidiomycetous endophytes, such as Ceratobasidium sp., and C. cornigerum, are reported in this study for the first time in bitter melon, and the results show that endophytic fungi from bitter melon exhibit a high biodiversity.

Many phylogenetic studies involving fungi rely on the analysis of ribosomal DNA, in particular the internal transcribed spacer (ITS) regions, to assist in separation at the genus and species levels [35] [36]. Based on phylogenetic analysis of endophytes associated with bitter melon, the ITS sequences successfully separate species, such as F. solani, F. kyushuense, C. verrucosus, C. globosum, E. rostratum, C. brachyspora, C. verruculosus, C. affinis, $P$. bougainvilleicola, $P$. longicolla, $P$. glabrae, $P$. verruculosum, $P$. oxalicum, $P$. citrinum, $P$. chermesinum, P. glomerata, A. fumigatus and A. japonicas; but on the other hand, some isolates belonging to A. alternata, C. gloeosporioides, C. cladosporioides, C. brasiliense, C. convolutum, F. proliferatum, F. oxysporum, F. verticillioides, F. equiseti, F. camptoceras, Xylaria, require the analysis of others molecular markers to provide better taxonomic resolution. Rivera-Orduña et al. (2011) isolated and identified 116 endophytes of Taxus globosa (Mexican yew), and found that ITS sequences could not provide enough information to analysis of the isolates belonging to the families Xylariaceae and Pleosporomycetidae [28]. In addition, the fungal endophyte zly-17 is identified as a Phomopsis sp., and the phylogenetic analyses based on ITS1, ITS2, and 5.8 ribosomal RNA gene show that this fungal isolate is closely related to P. longicolla (GenBank accession number EU650789).

The present study clarifies phylogenetic relationships among endophytes associated with bitter melon. Molecular analyses of rDNA are proven to be useful for identification of endophytes. In the classification of endophytes, it is necessary to consider an integrated approach, such as molecular phylogeny, host, colony growth rate, symptoms, and shape of conidia.

\section{Acknowledgements}

I would like to thank Dr. Tom Hsiang for his comments and suggestions on this manuscript. The research work was granted from Provincial Natural Science Foundation Team Project of Guangdong Province, China (No. E05202480), State technology project item of Guangdong Province, China (No. 20052040102) and Foundation of Zhongkai University of Agriculture and Engineering (No. G3071202).

\section{References}

[1] Arnold, A.E., Maynard, Z., Gilbert, G.S., Coley, P.D. and Kursar, T.A. (2000) Are Tropical Fungal Endophytes Hyperdiverse? Ecology Letters, 3, 267-274. http://dx.doi.org/10.1046/j.1461-0248.2000.00159.x

[2] Suryanarayanan, T.S., Murali, T.S. and Venkatesan, G. (2002) Occurrence and Distribution of Fungal Endophytes in Tropical Forests across a Rainfall Gradient. Canadian Journal of Botany, 80, 818-826. http://dx.doi.org/10.1139/b02-069

[3] Promputtha, I., Lumyong, S., Dhanasekaran, V., McKenzie, E.H.C., Hyde, K.D. and Jeewon, R. (2007) A Phylogenetic Evaluation of Whether Endophytes Become Saprotrophs at Host Senescence. Microbial Ecology, 53, 579-590. http://dx.doi.org/10.1007/s00248-006-9117-x 
[4] Rosa, L.H., Aline, B.M.V., Caligiorne, R.B., Campolina, S. and Rosa, C.A. (2009) Endophytic Fungi Associated with the Antarctic Grass Deschampsia antarctica Desv. (Poaceae). Polar Biology, 32, 161-167. http://dx.doi.org/10.1007/s00300-008-0515-z

[5] de Siqueira, V.M., Conti, R., de Araújo, J.M. and Souza-Motta, C.M. (2011) Endophytic Fungi from the Medicinal Plant Lippia sidoides Cham. and Their Antimicrobial Activity. Symbiosis, 53, 89-95. http://dx.doi.org/10.1007/s13199-011-0113-7

[6] Lin, X., Lu, C.H., Huang, Y.J., Zheng, Z.H., Su, W.J. and Shen, Y.M. (2007) Endophytic Fungi from a Pharmaceutical Plant, Camptotheca acuminata: Isolation, Identification and Bioactivity. World Journal of Microbiology and Biotechnology, 23, 1037-1040. http://dx.doi.org/10.1007/s11274-006-9329-8

[7] Hyde, K.D. (2001) Where Are the Missing Fungi? Does Hong Kong Have Any Answers? Mycological Research, 105, 1514-1518. http://dx.doi.org/10.1017/S0953756201004889

[8] Photita, W., Lumyong, S., Lumyong, P. and Hyde, K.D. (2001) Endophytic Fungi of Wild Banana (Musa acuminata) at Doi Suthep Pui National Park, Thailand. Mycological Research, 105, 1508-1513. http://dx.doi.org/10.1017/S0953756201004968

[9] Bérdy, J. (2005) Bioactive Microbial Metabolites. Journal of Antibiotics, 58, 1-26. http://dx.doi.org/10.1038/ja.2005.1

[10] Fernandes, N.P., Lagishetty, C.V., Panda, V.S. and Naik, S.R. (2007) An Experimental Evaluation of the Antidiabetic and Antilipidemic Properties of a Standardized Momordica charantia Fruit Extract. BMC Complement. BMC Complementary and Alternative Medicine, 7, 29. http://dx.doi.org/10.1186/1472-6882-7-29

[11] Limtrakul, P., Khantamat, O. and Pintha, K. (2004) Inhibition of P-Glycoprotein Activity and Reversal of Cancer Multidrug Resistance by Momordica charantia Extract. Cancer Chemotherapy and Pharmacology, 54, 525-530. http://dx.doi.org/10.1007/s00280-004-0848-4

[12] Sette, L.D., Passarini, M.R.Z., Delarmelina, C., Salati, F. and Duarte, M.C.T. (2006) Molecular Characterization and Antimicrobial Activity of Endophytic Fungi from Coffee Plants. World Journal of Microbiology and Biotechnology, 22, 1185-1195. http://dx.doi.org/10.1007/s11274-006-9160-2

[13] Chen, Y.X., Zhang, L.P. and Lu, Z.T. (2008) Analysis of the Internal Transcribed Spacer (ITS) Sequences in rDNA of 10 Strains of Fusarium spp. Journal of Anhui Agricultural Sciences, 36, 4886-4887.

[14] Schulz, B., Wanke, U. and Draeger, S. (1993) Endophytes from Herbaceous and Shrubs: Effectiveness of Surface Sterilization Methods. Mycological Research, 97, 1447-1450. http://dx.doi.org/10.1016/S0953-7562(09)80215-3

[15] Song, Z.H., Ding, L.X., Ma, B.J. and Li, W.Z. (1999) Studies on the Population and Dynamic Analysis of Peanut Endophytes. Acta Phytophylacica Sinica, 26, 309-314.

[16] Lee, S.B. and Taylor, J.W. (1990) Isolation of DNA from Fungal Mycelia and Single Spores. In: Innis, M.A., Gelfand, D.H., Sninsky, J.J. and White, T.J., Eds., PCR Protocols: A Guide to Methods and Applications, Academic Press, San Diego, 282-287. http://dx.doi.org/10.1016/b978-0-12-372180-8.50038-x

[17] White, T.J., Bruns, T., Lee, S. and Taylor, J. (1990) Amplification and Direct Sequencing of Fungal Ribosomal RNA Genes for Phylogeentics. In: Innis, M.A., Gelfand, D.H., Sninsky, J.J. and White, T.J., Eds., PCR Protocols: A Guide to Methods and Applications, Academic Press, San Diego, 315-322.

[18] Thompson, J.D., Gibson, T.J., Plewniak, F., Jeanmougin, F. and Higgins, D.G. (1997) The CLUSTALX Windows Interface: Flexible Strategies for Multiple Sequence Alignment Aided by Quality Analysis Tools. Nucleic Acids Research, 25, 4876-4882. http://dx.doi.org/10.1093/nar/25.24.4876

[19] Tamura, K., Dudley, J., Nei, M. and Kumar, S. (2007). MEGA 4 : Molecular Evolutionary Genetics Analysis (MEGA) Software. Version 4.0. Molecular Biology and Evolution, 24, 1596-1599. http://dx.doi.org/10.1093/molbev/msm092

[20] Kumar, S., Tamura, K. and Nei, M. (2004) $\mathrm{MEGA}_{3}$ : Intergrated Software for Molecular Evolutionary Genetics Analysis and Sequence Alignment. Brief Bioinformatics, 5, 150-163. http://dx.doi.org/10.1093/bib/5.2.150

[21] Guo, L.D., Hyde, K.D. and Liew, E.C.Y. (2001) Detection and Identification of Endophytic Fungi within Frond Tissues of Livistona chinensis Based on rDNA Sequence. Molecular Phylogenetics and Evolution, 20, 1-13. http://dx.doi.org/10.1006/mpev.2001.0942

[22] Guo, L.D., Huang, G.R., Wang, Y., He, W.H., Zheng, W.H. and Hyde, K.D. (2003) Molecular Identification of White Morphotype Strains of Endophytic Fungi from Pinus tabulaeformis. Mycological Research, 107, 680-688. http://dx.doi.org/10.1017/S0953756203007834

[23] Promputtha, L., Jeewon, R., Lumyong, S., Mckenzie, E.H.C. and Hyde, K.D. (2005) Ribosomal DNA Fingerprinting in the Identification of Non-Sporuating Endophytes from Magnolia liliifera (Magnoliaceae). Fungal Diversity, 20, 167186.

[24] Wang, Y., Guo, L.D. and Hyde, K.D. (2005) Taxonomic Placement of Sterile Morphotypes of Endophytic Fungi from Pinus tabulaeformis (Pinaceae) in Northeast China Based on rDNA Sequences. Fungal Diversity. 20, 235-260. 
[25] Wang, Y.T., Lo, H.S. and Wang, P.H. (2008) Endophytic Fungi from Taxus mairei in Taiwan: First Report of Colletotrichum Gloeosporioides as an Endophyte of Taxus mairei. Botanical Studies, 49, 39-43.

[26] Liu, K.H., Ding, X.W., Deng, B.W. and Chen, W.Q. (2009) Isolation and Characterization of Endophytic Taxol-Producing Fungi from Taxus chinensis. Journal of Industrial Microbiology \& Biotechnology, 36, 1171-1177. http://dx.doi.org/10.1007/s10295-009-0598-8

[27] Caruso, M., Colombo, A.L., Fedeli, L., Pavesi, A., Quaroni, S., Saracchi, M. and Bentrella, G. (2000) Isolation of Endophytic Fungi and Actinomycetes Taxane Producers. Annals of Microbiology, 50, 3-13.

[28] Rivera-Orduña, F.N., Suarez-Sanchez, R.A., Flores-Bustamante, Z.R., Gracida-Rodriguez, J.N. and Flores-Cotera, L.B. (2011) Diversity of Endophytic Fungi of Taxus globosa (Mexican Yew). Fungal Diversity, 47, 65-74. http://dx.doi.org/10.1007/s13225-010-0045-1

[29] Kharwar, R.N., Gond, S.K., Kumar, A. and Mishra, A. (2010) A Comparative Study of Endophytic and Epiphytic Fungal Associated with Leaf of Eucalyptus citriodora Hook, and Their Antimicrobial Activity. World Journal of Microbiology and Biotechnology, 26, 1941-1948. http://dx.doi.org/10.1007/s11274-010-0374-y

[30] Kharwar, R.N., Verma, S.K., Mishra, A., Gond, S.K., Sharma, V.K., Afreen, T. and Kumar, A. (2011) Assessment of Diversity, Distribution and Antibacterial Activity of Endophytic Fungi Isolated from a Medicinal Plant Adenocalymma alliaceum Miers. Symbiosis, 55, 39-46. http://dx.doi.org/10.1007/s13199-011-0142-2

[31] Sánchez Márquez, S., Bills, G.F. and Zabalgogeazcoa, I. (2007) The Endophytic Mycobiota of the Grass Dactylis glomerata. Fungal Diversity, 27, 171-195.

[32] Sánchez Márquez, S., Bills, G.F., Dominguez, A.L. and Zabalgogea, I. (2010) Endophytic Mycobiota of Leaves and Roots of the Grass Holcus lanatus. Fungal Diversity, 41, 115-123. http://dx.doi.org/10.1007/s13225-009-0015-7

[33] Thomas, S.E., Crozier, J., Aime, M.C., Evans, H.C. and Holmes, K.A. (2008) Molecular Characterization of Fungal Endophytic Morphospecies Associated with the Indigeneous Forest Tree, Theobroma gileri, in Ecuador. Mycological Research, 112, 852-860. http://dx.doi.org/10.1016/j.mycres.2008.01.008

[34] Pinruan, U., Rungjindamai, N., Choeyklin, R., Lumyong, S., Hyde, K.D. and Jones, E.B.G. (2010) Occurrence and Diversity of Basidiomycetous Endophytes from the Oil Palm, Elaeis guineensis in Thailand. Fungal Diversity, 41, 7188. http://dx.doi.org/10.1007/s13225-010-0029-1

[35] Beever, R.E. and Weeds, P.L. (2004) Taxonomy and Genetic Variation of Botrytis and Botryotinia. In: Elad, Y., Williamson, B., Tudzynski, P. and Delan, N., Eds., Botrytis: Biology, Pathology and Control, Kluwer Academic Publishers, Dordrecht, 29-52.

[36] White, T.J., Bruns, T.D., Lee, S. and Taylor, J. (1990) Amplification and Sequencing of Fungal Ribosomal RNA Genes for Phylogenetics. In: Innis, M.A., Gelfand, D.H., Sninsky, J.J. and White J.J., Eds., PCR Protocols: A Guide to Methods and Applications, Academic Press, San Diego, 315-322. http://dx.doi.org/10.1016/b978-0-12-372180-8.50042-1 